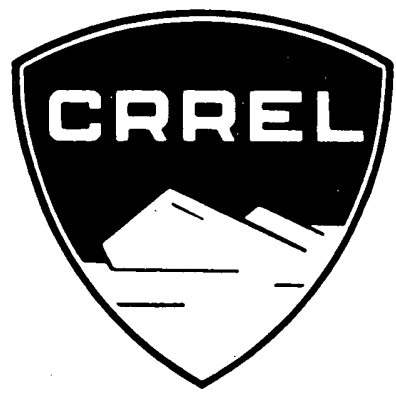

Research Report 253

\title{
EVALUATION OF FOREST CANOPIES BY PHOTOGRAPHY
}

\author{
Philip L. Johnson \\ and \\ Theodore C. Vogel
}

October 1968

\section{U.S. ARMY MATERIEL COMMAND \\ TERRESTRIAL SCIENCES CENTER \\ COLD REGIONS RESEARCH \& ENGINEERING LABORATORY}

HANOVER, NEW HAMPSHIRE 


\section{PREF ACE}

The investigations reported here were supported primarily by in-house project funds. Various scientists and their organizations have cooperated in the several experiments in which the technique was applied and refined; they are referenced in the appropriate sections.

The work was performed by Dr. Philip L. Johnson (Ecologist) and Mr. Theodore C. Vogel (Research Forester) under the general supervision of Mr. Robert E. Frost (Chief, Photographic Interpretation Research Division) of the Cold Regions Research and Engineering Laboratory, U.S. Army Terrestrial Sciences Center (USA TSC). Appreciation is expressed to Dr. E.B. Knipling for reviewing portions of the manuscript and to SP S.A. Scanga for assisting with the data reduction.

Citation of commercial products or manufacturers is for information only and does not constitute official endorsement or approval.

USA TSC is a research activity of the Army Materiel Command. 


\section{CONTENTS}

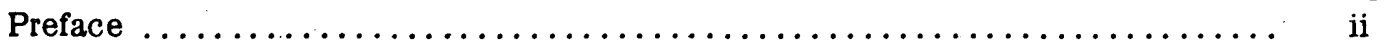

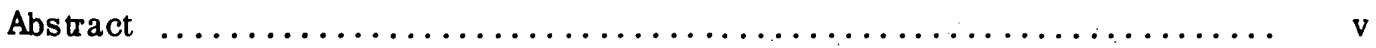

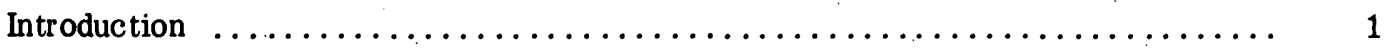

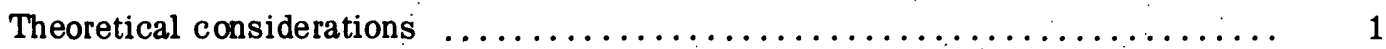

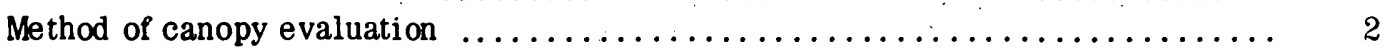

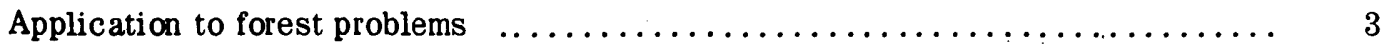

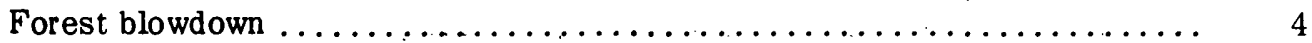

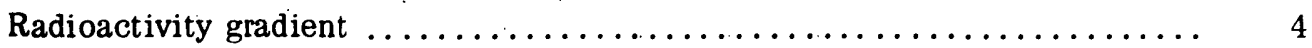

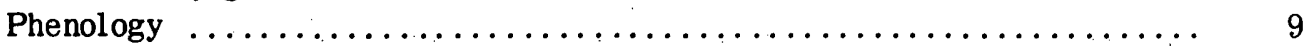

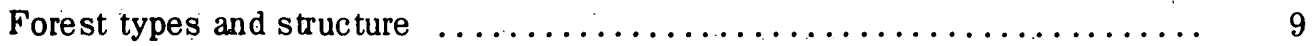

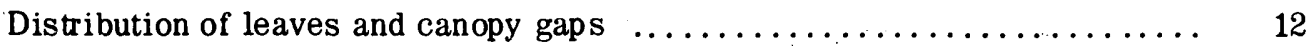

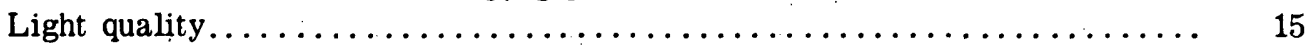

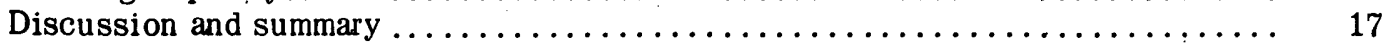

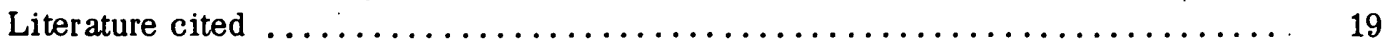

Figure

\section{ILLUSTRATIONS}

1. A macrodensitometer for measuring light transmission through large trans-

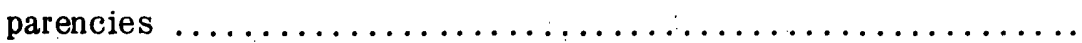

2. Hemispherical photographs at increasing distances from ground zero before and after a large explosion in a conifer forest (Sta. $5,6,7) \ldots \ldots \ldots$

3. Hemispherical photographs at increasing distances from ground zero before and after a large explosion in a conifer forest (Sta. 8,9,10) .......

4. The relationship of CCI to distance from ground zero before and after a

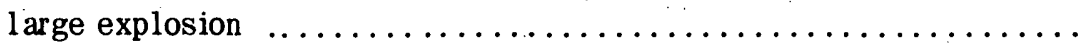

5. The relationship between the radiation gradient, CCI on two dates, and optical density of aerial photography with distance from a source of

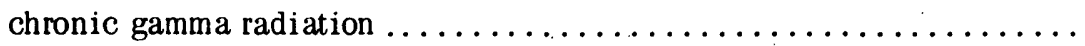

6. A gradient of radiation effects radiating with distance from a high energy point source in a pine-hardwood forest is illustrated by hemispherical

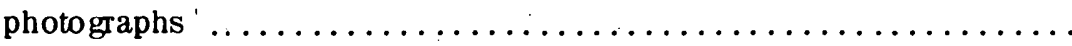

7. The phenology of a northern hardwood forest illustrated by hemispherical

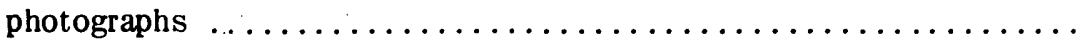

8. The phenology of the forest canopy at Hubbard Brook Experimental Forest is shown by a progression of CCI values $\ldots \ldots \ldots \ldots \ldots \ldots \ldots$

9. Hemispherical photography of contrasting forest types $\ldots \ldots \ldots \ldots \ldots$

10. Target detectability in relation to angle from zenith as analyzed from hemispherical photography from three different forest types $\ldots \ldots \ldots \ldots \ldots$

11. Comparis on of CCI values at different heights in a forest with a vertical profile of leaf numbers in a Panamanian semi-evergreen forest .....

12. Sunlight and forest shade light intensity by wavelength in a Puerto Rican evergreen montane rain forest $\ldots \ldots \ldots \ldots \ldots \ldots \ldots \ldots \ldots \ldots$

13. Winter and summer light intensity by wavelength on the forest floor of a northern hardwood forest in New Hampshire 


\section{TABLES}

Table

Page

I. Forest types of interior Alaska, population parameters and associated canopy

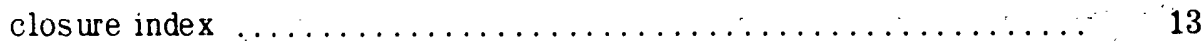

II. Conventional canopy photographs of tropical forests, Costa Rica .........

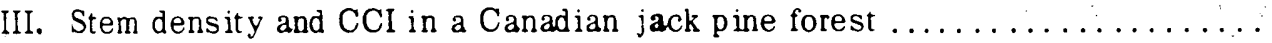
13

IV. Comparison of Canopy Closure Index (CCI) with measurements of solar energy 14 penetrating to the forest floor at Hubbard Brook Experimental Forest 


\begin{abstract}
A technique for evaluating forest canopies was developed based on the use of a divergent lens system to obtain hemispherical photographs of tree crowns. The photography was processed from $35 \mathrm{~mm}$ film and enlarged as a silhouette, and the light transmission was measured with a specially fabricated macrodensitometer. It is concluded that the amount of forest canopy can be expressed as camopy closure index (CCI) at a precision of approximately $5 \%$.

It is shown by application to a variety of problems in diverse geographical areas that this technique can be used for measuring both temporal and spatial changes in the canopy, for estimating the shade light climate, and for specifying the probability of target detection through a canopy. Data are presented to analyze changes caused by explosions, radioactivity, growing season, and vegetation types. The geometry of gaps in tree crowns is discussed and the nature of shade light quality under forests is illustrated.
\end{abstract}




\title{
EVALUATION OF FOREST CANOPIES BY PHOTOGRAPHY
}

\author{
by
}

Phil ip L. Johnson and Theodore C. Vogel

\section{INTRODUCTION}

The quantity and quality of solar radiation received on a forest floor as contrasted with a clearing is primarily a function of the canopy. : The development of a closed or nearly closed canopy confers stability on the forest ecosystem in which species diver sity is usually high and leaf area is optimized for a large standing crop, but a low annual net community production. : As a result, plant succession may occur quite rapidly in proportion to a change in crown closure. : Species and communities occupying subordinate strata within the forest have evolved life histories as well as physiological and structural adaptations compatible with the phenology of the canopy or a shade light environment.

Many ecological and military problems require a measure of the light attenuation by a forest, its canopy distribution, and its degree of closure. Various devices such as photographic exposure meters (Bormann, 1956), pinhole cameras (Brown, 1962) and conventional cameras (Rinker et al., 1963) have been used to estimate the canopy configuration or total shade light received at a point on the forest floor, but they do not provide a measure of light distribution or of the canopy geometry presented to a seedling or target beneath the forest canopy. The light intensity at the forest floor can be estimated mathematically if solar intensity, sun angle, leaf area and leaf extinction coefficient are known (Saeki, 1963; Monsi and Saeki, 1953). The objective of this report is to describe a method for evaluating canopy development by measuring the opaqueness of hemispherical photographs. : This technique has been applied to a number of contrasting problems requiring a measurement of the forest canopy.

\section{THEORETICAL CONSIDERATIONS}

There are two types of solar radiation in forests: diffuse and direct. Several recent reviews summarize the inter action of solar energy and forests (Saeki, 1963; Anderson, 1964a, 1966; Reifsnyder and Lull, 1965). The intensity of light $I$ penetrating a canopy at a given height is proportional to leaf area:

$$
I=I_{0} \exp -K F
$$

where: $I_{o}=$ light intensity in the open,

$F=$ leaf area index,

$K=$ extinction coefficient by analogy with Beers' law.

Assuming $K$ to be constant in a stand at a given stage of development, then, light attenuation approximates leaf area:

$$
\log \left(I / I_{0}\right) / / / F \text {. }
$$


The direct light component emanates from a point source which is represented over time by a solar track, the apparent path of the sun relative to local horizons. The amount of diffuse light penetrating a stand is the resultant of the probability of encountering a gap, foliage inclination angle, solar declination angle, and leaf area, all integrated over time.

It becomes apparent that a precise expression of light penetrating a forest as diff use and as sunfleck energy is difficult and clumsy, particularly if either the instrumentation or the processes under study are wavelength-dependent. Anders on (1964b) showed that reliable estimates of the average percentage of direct and of diffuse light could be obtained from hemispherical photographs. She constructed an equal irradiance grid to estimate the diffuse component and a solar tract diagram to account for the sunfleck contribution. This approach neglects transmission and reflectance by foliage.

The success of Anderson's computations of light climate and of our evaluation of canopy development derives from the use of a divergent lens system as opposed to the conventional convergent camera optics. Thus canopy gaps viewed at various angles and distances are not corrected for the apparent distortion but are imaged in the configuration presented to a target or to a seedling.

To obtain an expression of canopy development from this photography, the vegetation must be silhouetted against a lighter background. By transferring the photographic image obtained in the field to copy film in the darkroom, the silhouette is opaqued and the sky appears clear. In this way leaf extinction is not a problem and the subtle gradients of density in the sky resulting from nonuniform, overcast or noni sotropic lighting are avoided. Experience has shown that large errors may result on days of bright sunshine because of low contrast ratio in the photography from specular reflection from branch and stem surfaces. Therefore, our hemispherical photographs were obtained at midday during overcast conditions.

\section{METHOD OF CANOPY EVALUATION}

Hemispherical photographs were obtained at representative stations with a Nikon Model F camera and "fisheye" or hemispherical lens. At each station the camera was leveled on a tripod or permanent pipe $1 \mathrm{~m}$ above ground using a target spirit level. Film exposures were best determined with a light meter with a 3 degree acceptance angle. A high contrast negative was obtained by basing the original exposure on a sky reading. The $35 \mathrm{~mm}$ panchromatic film (Plus $\mathrm{X}$ ) was processed in Acufine following the manufacturer's recommendations. : The negatives were then enlarged seven times to a diameter of $170 \mathrm{~mm}$ on high contrast copy film (Kodalith Ortho Type III) and developed by the normal method. Quality control during enlargement was assisted by use of a spot photometer (Heathkit Fotoval Model Pm-14) to read sky density of are as as small as $0.3 \mathrm{~mm}^{2}$ in the or iginal negative.

To obtain an expression of canopy cover from these photogr aphs the transmitted light was measured in the center portion of the photogr aph corresponding to the 90 degree cone volume. Since the canopy volume in a cone is evaluated rather than some vertical projection of tree crowns, the term canopy closure index is adopted as less ambiguous than percent cover.

An optical density instrument (Fig. 1) was developed to determine canopy closure index. This macrodensitometer consists of four main components: 1) a variable resistor, A (Voltbox, Type UC1M), which controls the voltage supply; 2) a uniformly diffuse light source, $B$ (Glowbox Model $12-20)$; 3) a sensor assembly consisting of a phototube, F, and a light shield, E, centered above the masking templates, C and D; 4) a photometer, G (Photovolt Model 5-1-A), that amplifies and presents the signal as percent transmittance. The height $h$ of the phototube above the light field must be such that the chord subtending angle $\theta$, the acceptance cone of the phototube with opal diff using disk, is greater than the diameter of the light field: 


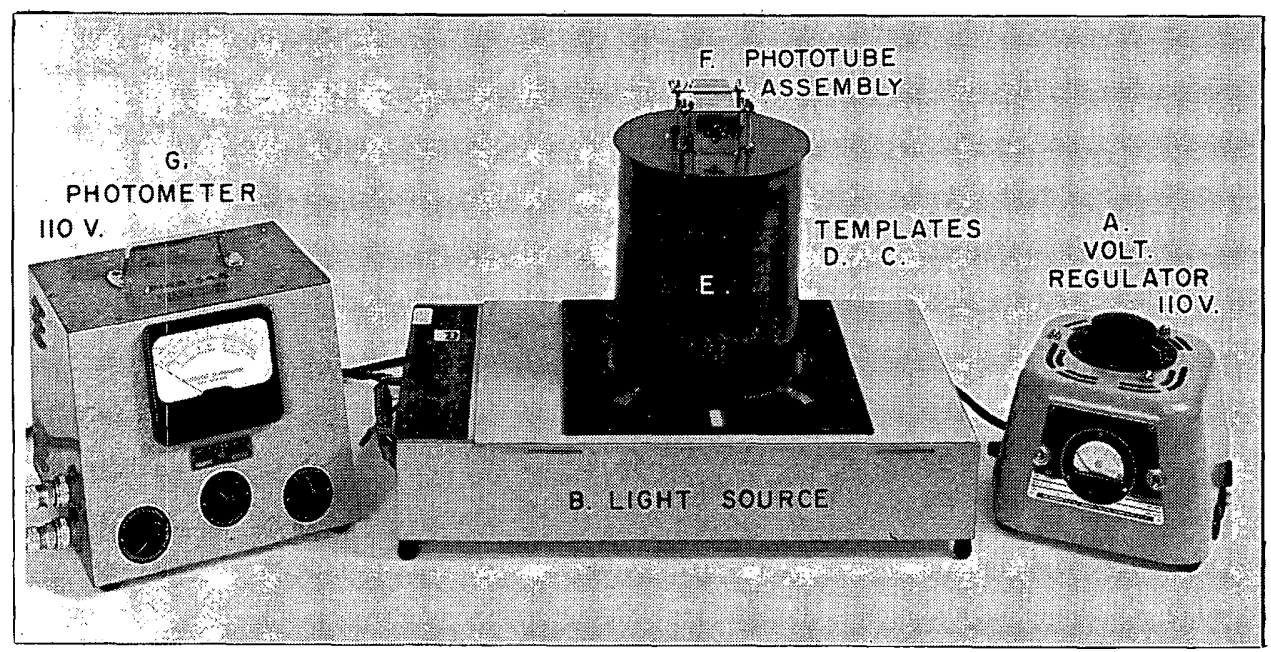

Figure 1. A macrodensitometer for measuring light transmission through large transparencies.

$$
h=\frac{1 / 2 \text { diameter }}{\tan 1 / 2 . \theta}=\frac{85 \mathrm{~mm}}{\tan 20^{\circ}}=\frac{85}{.3640}=23.6 \mathrm{~cm} .
$$

Therefore, the height of $26 \mathrm{~cm}$ was used. A unif orm light field is created by two 15-watt fluorescent lamps (GS $15 \mathrm{~T} 12 \mathrm{cw}$ ) beneath a $6-\mathrm{mm}$ opal plastic diffusion plate.

The light sensor is placed over the light box (Fig. 1) and centered above a template, C, in which a circle has been cut corresponding to the 170-mm diameter of the enlarged positive. The photometer is zeroed with the light off; then the light source is activated and adjusted with the variable resistor until $100 \%$ transmittance is registered on the photometer. If a sheet of unexposed but developed film is placed over the source during this calibration, the base density of the film may be automatically subtracted from the transmittance readings. Once the system is calibrated, each canopy positive is centered in sequence under the template and the amount of light attenuation read directly in percent transmittance. Since this value is equal to the amount of open area, it must be subtracted from 100 to equal canopy closure index.

A second template, $D$, was placed over the sample on the light field which limited the photo coverage to a $90^{\circ}$ cone. Although the selection of a $90^{\circ}$ cone volume is somewhat arbitrary until experience suggests a more optimum value, it was thought that this zone above a camera adequately represented the canopy overhead without undue bias from shrub strata or adjacent slopes. Thus

$$
\mathrm{CCI}=100-T_{90} \%
$$

\section{APPLICATION TO FOREST PKOBLEMS}

A variety of disturbances to a natural forest ecosystem, some accidental, other s caused by man's purposeful manipulation, can be evaluated by measuring the canopy closure index. Various timber harvest and thinning practices remove crown volume as well as merchantable biomass. Explosions, chemical defoliation and ionizing radiation are drastic treatments currently-associated with military activities or research into the consequences of modern technology. With the advent of thermal scanners and heat seeking missiles, the military has become interested in measuring 
the alignment of gaps through forest canopies, since infrared sensors respond only to direct lineof-sight signals. Conversely, the soldier is interested in the camouflage potential of various canopy configurations. This interest is of ten characterized by the ill-def ined terms vertical and horizontal visibility. Hemispherical photogr aphy is a simple, direct approach to many of these problems.

\section{Forest blowdown}

The effects of a high energy explosion on a forest canopy were, in part, evaluated with hemispherical photography (Vogel, 1967). The photographs (F ig. 2, 3) were taken at ten stations along a radius from ground zero immediately before and after the detonation of a 50-ton TNT charge. This Canadian forest was composed of white spruce, Picea glauca, and lodgepole pine, Pinus contorta, with an average height of $21 \mathrm{~m}$ and a diameter of $15 \mathrm{~cm}$. The stand was approximately 100 years old with an average stem spacing of 3 to $4 \mathrm{~m}$.

Independent evaluation of post-blast aerial photographs indicated seven distinct damage zones surrounding ground zero (Vogel, 1967). These were 1) the crater, 2) zone of complete stem removal, 3) stump zone, 4) prostrate stem zone, 5) prostrate tr ees with partial crowns, 6) leaning trees and 7) the unaffected forest. - In Figure 4 Stations 5 and 6 were in Zone 5; Stations 7-9 were in Zone 6 and Station 10 was in Zone 7, the undamaged forest.

The canopy closure indices were obtained with an area dot grid rather than the densitometer because of a broken cloud cover at the time of the post-blast photography which resulted in canopy photographs of varying sky density. A close relationship between the area dot grid values and the macrodensitometer values had been previously established (Johnson and Vogel, 1965). Before detonation, the forest CCI averaged $72 \%$ and ranged from $64 \%$ to $84 \%$. The post-blast values obtained from the same locations indicated complete crown removal from Stations 1-6 with a sharp increase in crown survival beginning at Station 7 and continuing to $58 \%$ at Station 10 (Fig. 3, 4). A portion of the difference between pre- and post-blast CCI at Station 10 is experimental error, but an increase in green ground litter at this station following the blast indicated partial needle fall at this distance from ground zero.

\section{Radioactivity gradient}

Ionizing radiation is one of the few environmental factors which man can regulate and vary in intensity with fewer direct interactions with the rest of the holocoenotic environment. At the Brookhaven National Laboratory, Long Island, N. Y., an experiment was conducted to study the response of a simple forest ecosystem to chronic gamma irradiation (Woodwell and Rebuck, 1967). A spatial gradient of vegetation response was established surrounding and radiating from the radiation source as a result of the dispersion of species with differing radiosensitivities (Fig. 6). Monitoring of this gr adient (Johnson, 1965) with several types of aerial film provided a close $(r=0.88)$ relationship in 1963 between optical density of a panchromatic film and the logarithm of gamma dosage in roentgens/day (Fig. 5).

Two sets of hemispherical photography were obtained at $20-\mathrm{m}$ increments along a radius from the gamma source at a height of $1.5 \mathrm{~m}$. The first set was taken in June 1963 and the second set in June 1966. The correlation coefficient between the two sets of CCI values was $r=0.98$, yet it would appear from the shapes of the curves in Figure 5 that a steepening of the gradient has occurred in the intervening 3 years with comparatively little further recession of the forest surrounding the source.

These hemispherical photographs can also be compared with the aerial photography flown in June 1963. Correlation of CCI values with optical density of the panchromatic film (Fig. 5) yielded correlation coefficients of $r=0.97$ in 1963 and $r=0.95$ in 1966. Thus hemispherical photography can describe a gradient of spatially changing canopy coverage. 

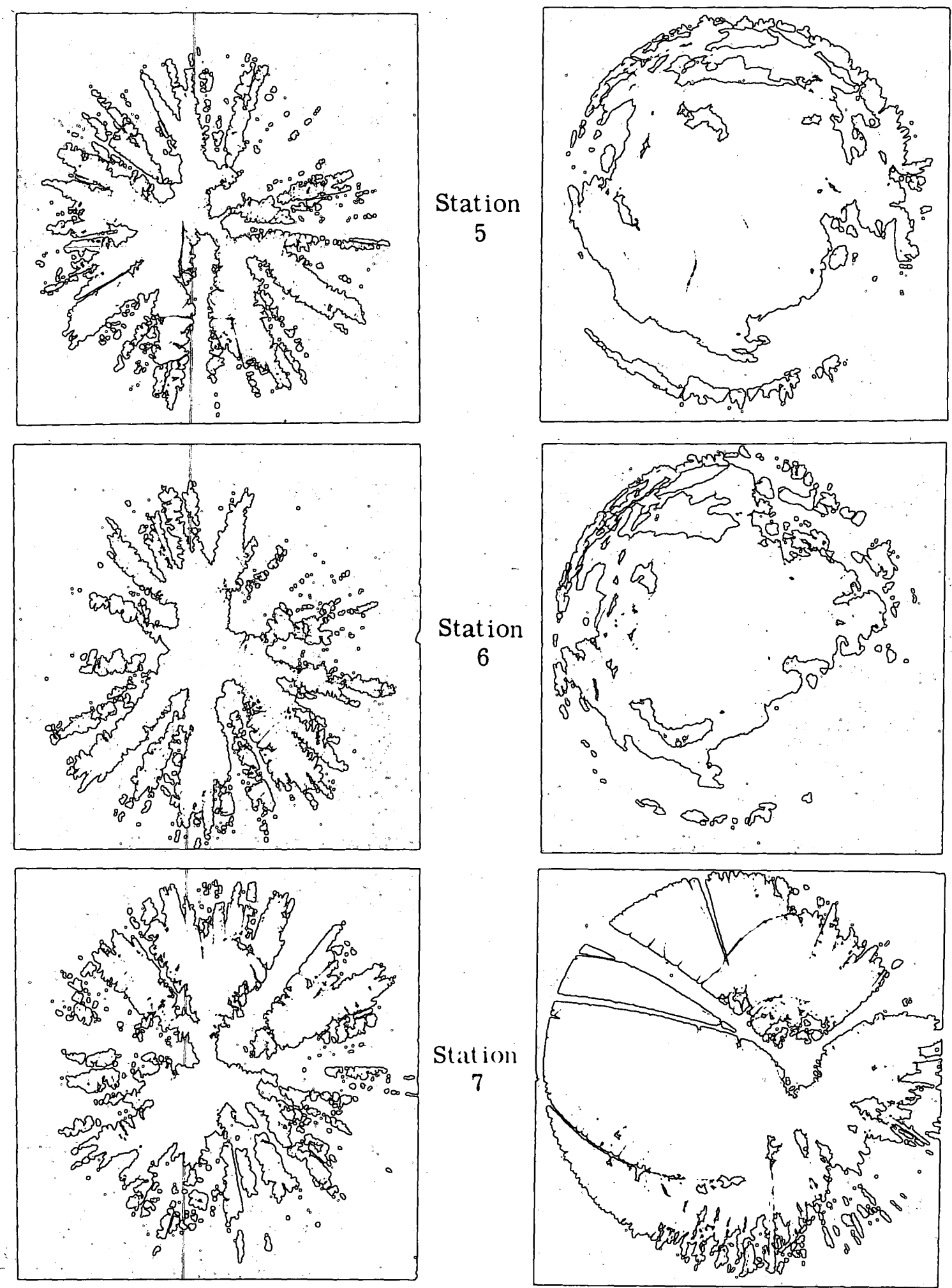

Figure 2. Hemispherical photographs at increasing distances from ground zero before and after a large explosion in a conifer forest (Stations $5,6,7)$. 

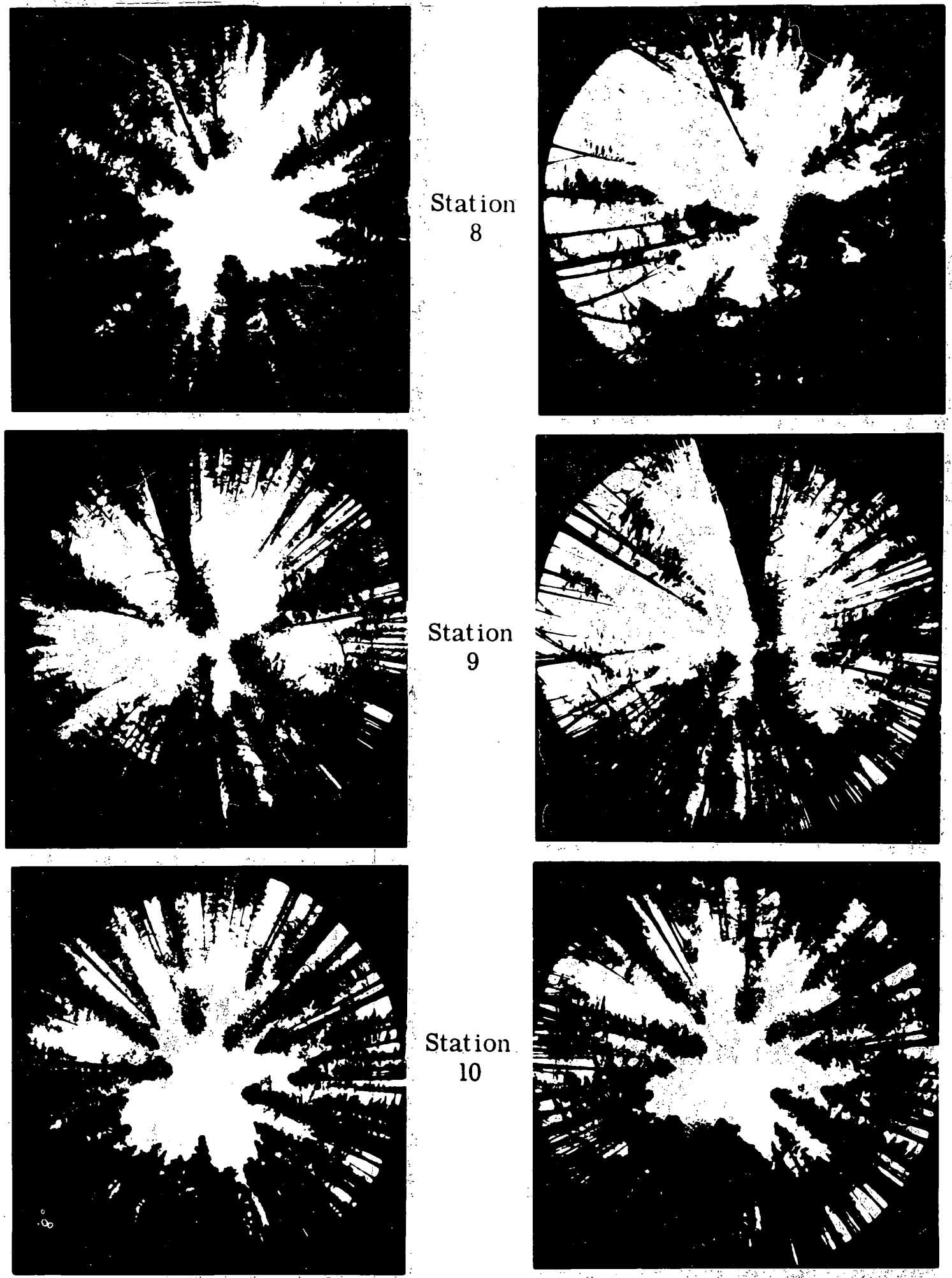

'Figure 3. Hemispherical photographs at increasing distances from ground zero before and after a large explosion in a conifer forest (Stations $8,9, \% 10$ ). 


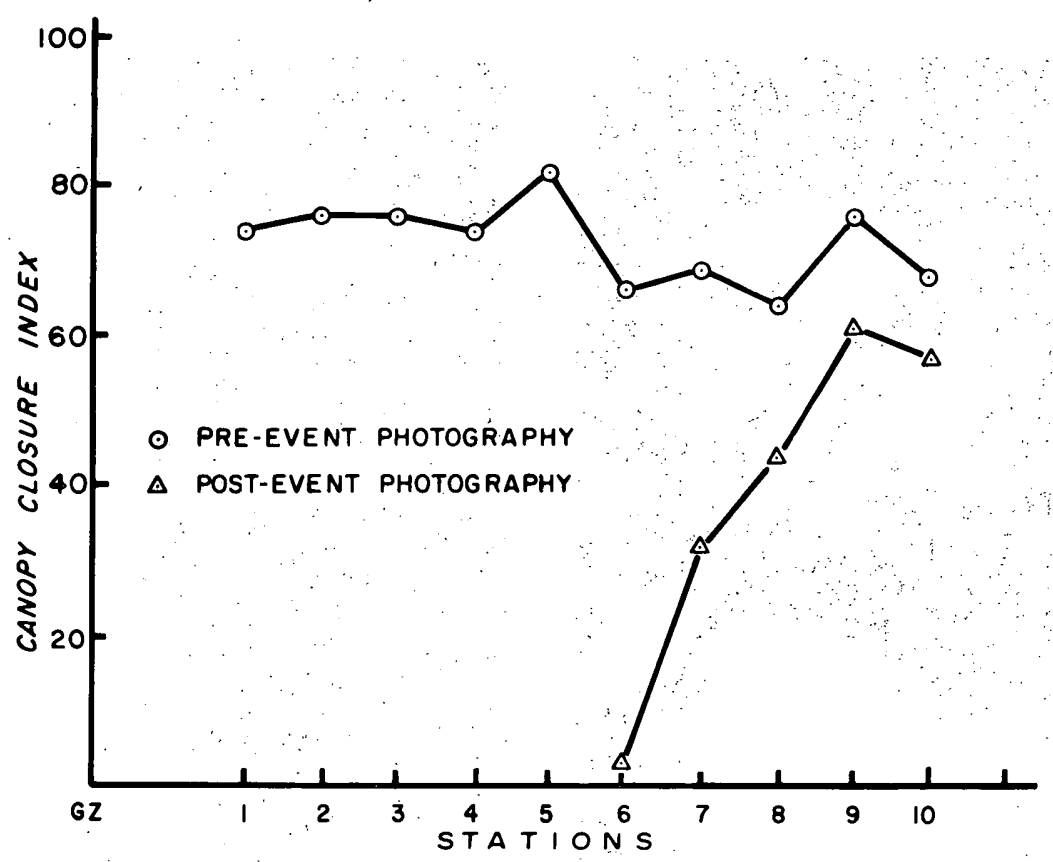

Figure 4. The relationship of $\mathrm{CCI}$ to distance from ground zero be-

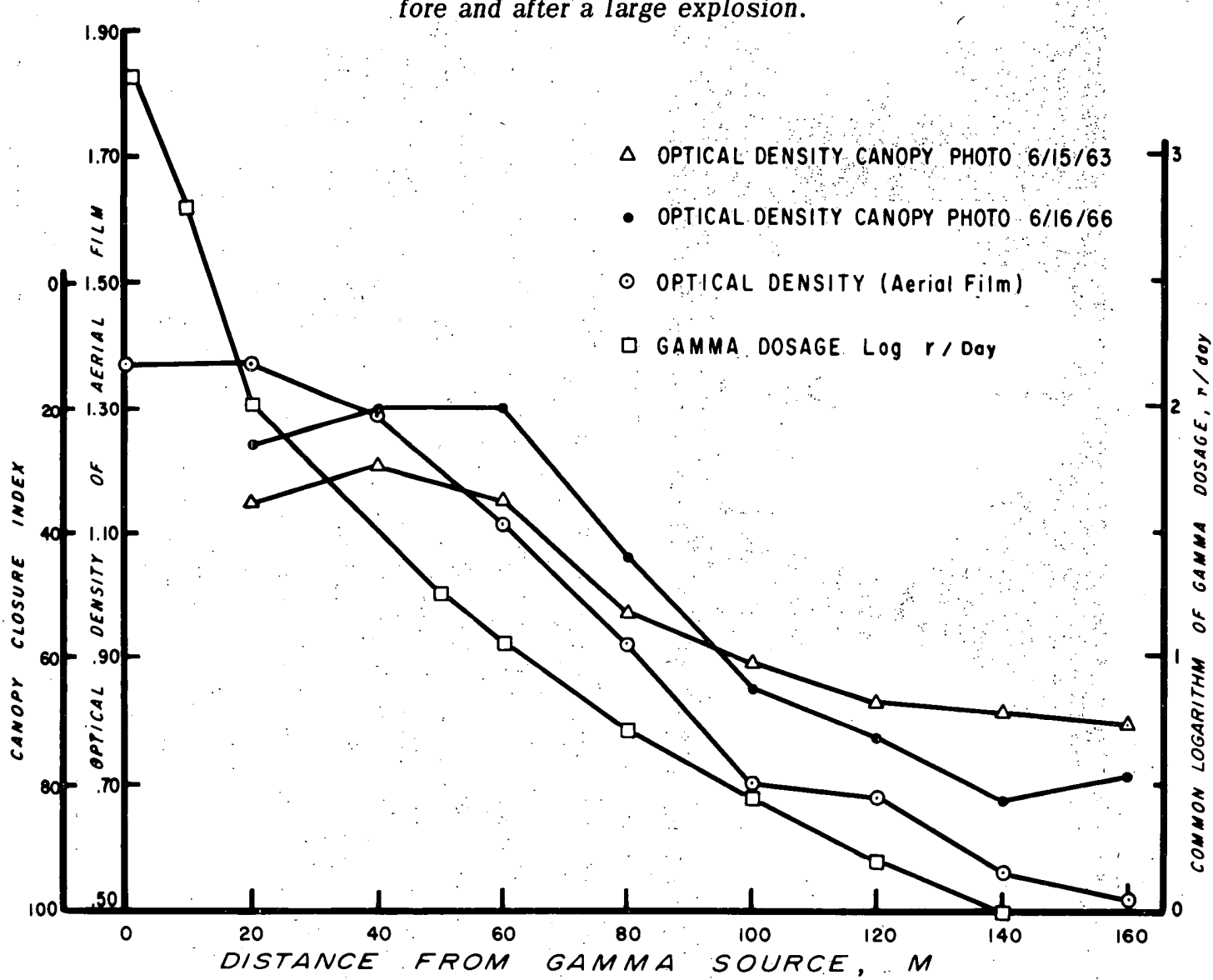

Figure 5. The relationship between the radiation gradient, $\mathrm{CCI}$ on two dates, and optical density of aerial photography with distance from a source of chronic gamma radiation. 


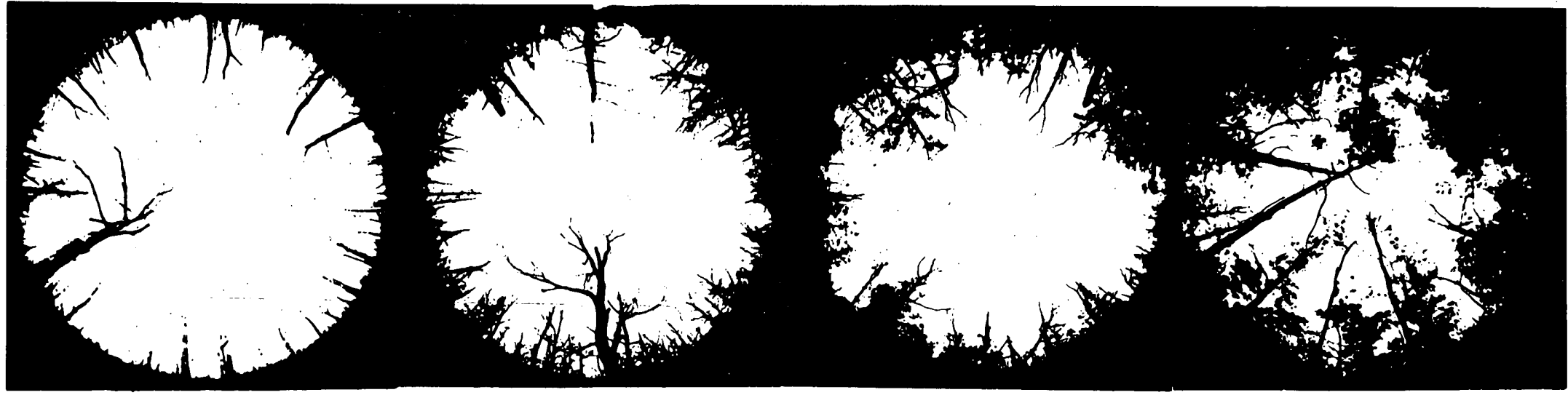

20 meters

40 meters

60 meters

80 meters

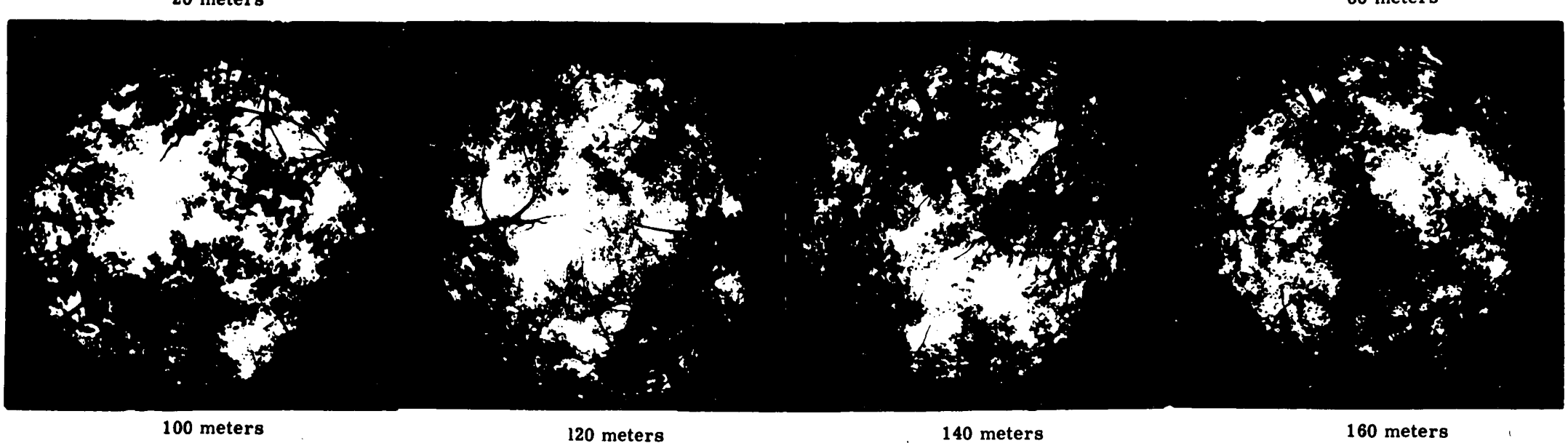

Figure 6. A gradient of radiation effects radiating with distance from a high energy point source in a pine-hardwood forest is illustrated by hemispherical photographs. 


\section{Phenology}

While forest canopies lessen the magnitude of many climatic variables within the stand and alter the distribution of others, such as precipitation, they also impose a highly variable light regime both spatially and temporally associated with sunflecks. In deciduous forests seasonal periodicity is still a further complexity to which the vernal flora have evolved. The amount of solar energy reaching the forest floor is the sum of direct sunlight (sunflecks) plus diffuse sky light, plus a smaller fraction of light reflected from and transmitted through the foliage. The condition of the forest canopy and the light climate it achieves can be measured and expressed as canopy closure index from hemispherical photography.

To evaluate the phenological changes in a northern hardwood forest, 12 permanent photo stations were established on Watershed 6 of the Hubbard Brook Experimental Forest, West Thornton, N.H., in cooperation with a hydrolog ic and mineral cycling project conducted by the U.S. Forest Service and Dartmouth College (Bormann and Likens, 1967). Paired pipes, $1 \mathrm{~m}$ high, were dispersed in elevation increments of $30 \mathrm{~m}$ in this $130-\mathrm{km}^{2}$ watershed. Hemispherical photographs were obtained throughout the growing season in 1966 and 1967. A representative series from Station 2 (Fig. 7) illustrates the seasonal progression of a single year's leaf production.

The CCI values derived on these nine dates are plotted in Figure 8 to illustrate the rather abrupt vernal and autumnal changes in the forest canopy. A greater number of replications in 1967 helped to refine this essentially similar phenological curve for 1967. It was evident that crown development was delayed approximately 5 days in 1967 due to a cold spring throughout the region. The leaf expansion was compressed into a shorter time in 1967.

Independent confirmation was provided by B. Mahall* who observed and recorded morphological development of both ground and canopy flora weekly in 1966 on Watershed 6. His data indicated bud swelling on 15 May, bud swelling and opening on 22 May, rapid leaf expansion on 27 May and full leaf expansion by the end of the first week in June with respect to maple, Acer saccharum, and beech, Fagus grandiflora, in the over story. Lower elevations were more advanced than upper elevations, seedlings and saplings were more advanced than the same species in the overstory, and maple initiated leaf expansion before beech. These observations mesh completely with the CCI values obtained at the 12 stations during the same period. A series of hemispherical photogr aphs from a wet tropical forest in Puerto Rico obtained periodically over a 30-month period supported the lack of a seasonal periodicity in that forest canopy (Johnson and Atwood, 1968). The average CCI for this tropical forest was 86.5 .

\section{Forest types and structure}

The range of expected CCI values in closed crown stands is probably not great. It is evident: from defoliated and from deciduous forests that values approaching $50 \%$ are to be expected due to the cross-sectional area of twigs, br anches and stems. Values greater than $90 \%$ are seldom obtained. From the rationale of eq 1 the argument has been advanced (Anderson, 1966) for an optimal leaf area index, although successional stands may not have reached such a value, or perhaps

* Personal communication, 1967. 


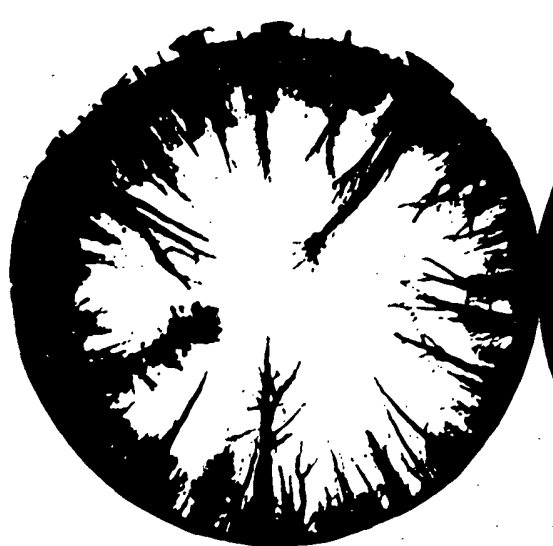

April 7.' 1966
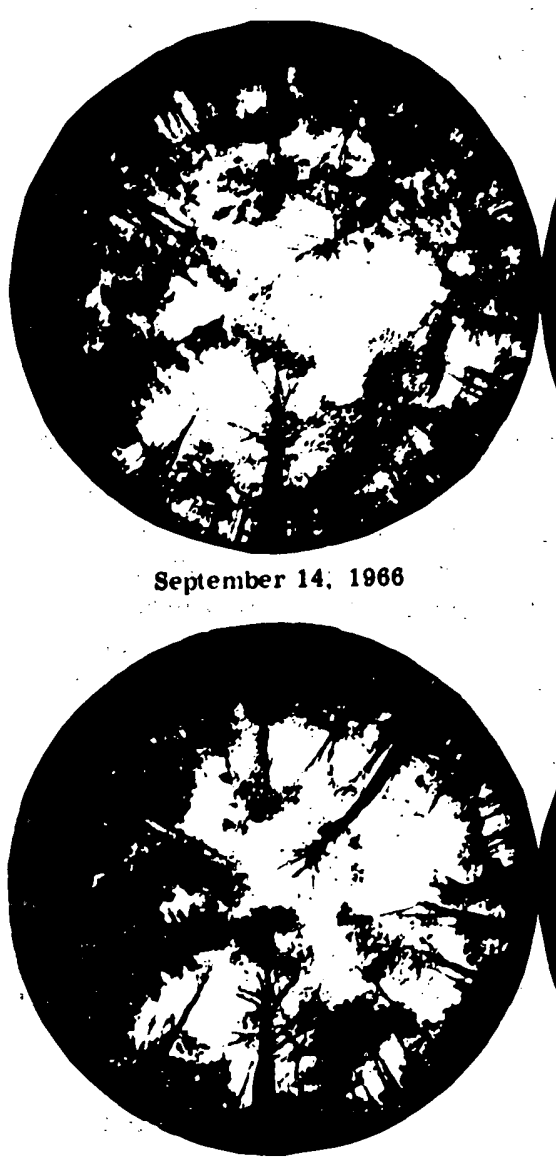

Ortuber 7. 1966

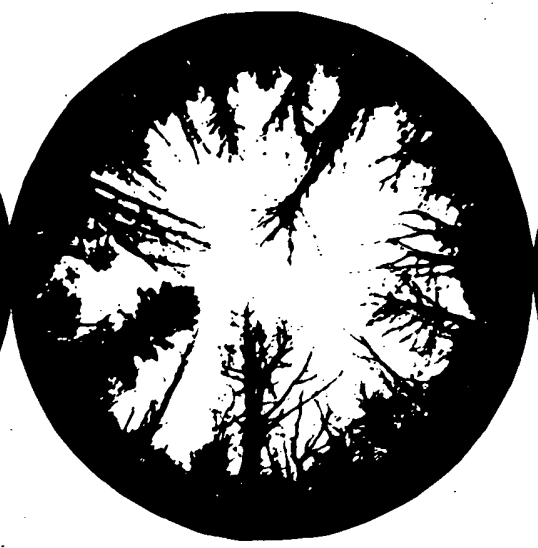

April 16. 1966

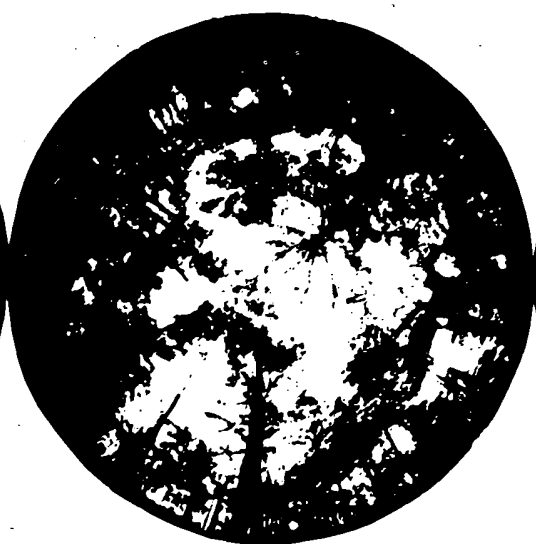

September 21, 1966

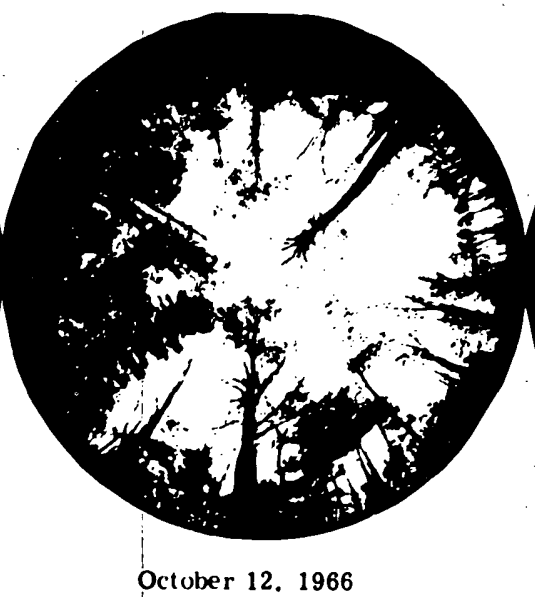

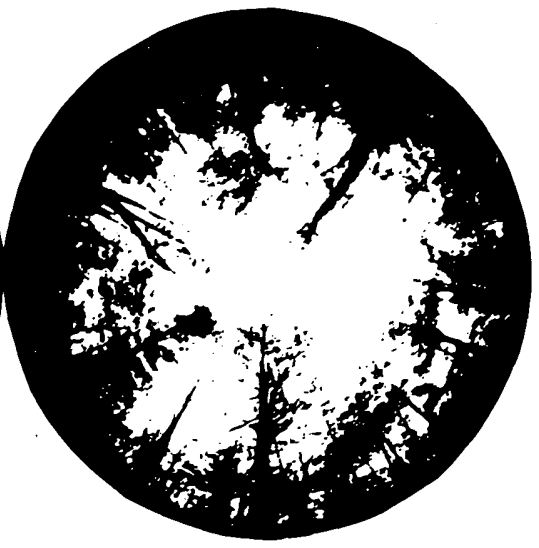

June 1. 1966

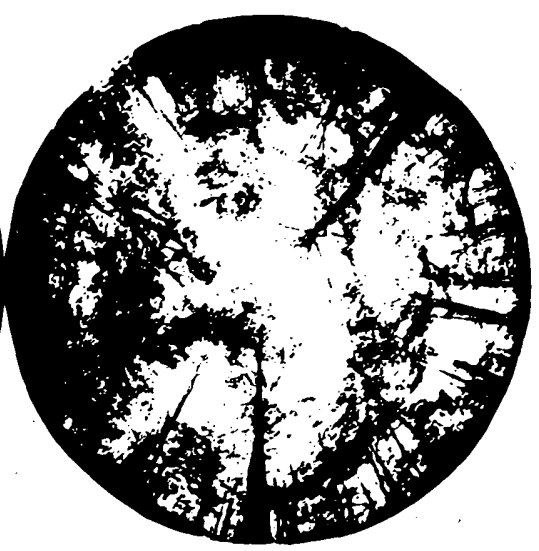

September 28, 1966

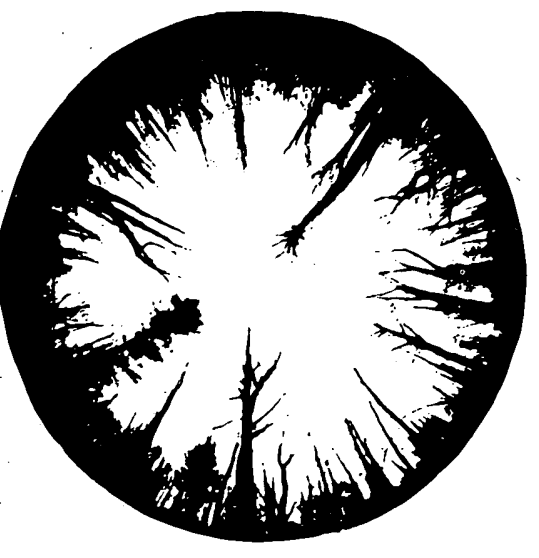

Norember 9. 1966

Figure 7. The phenology of a northern hardwood forest illustrated by hemispherical photographs. 


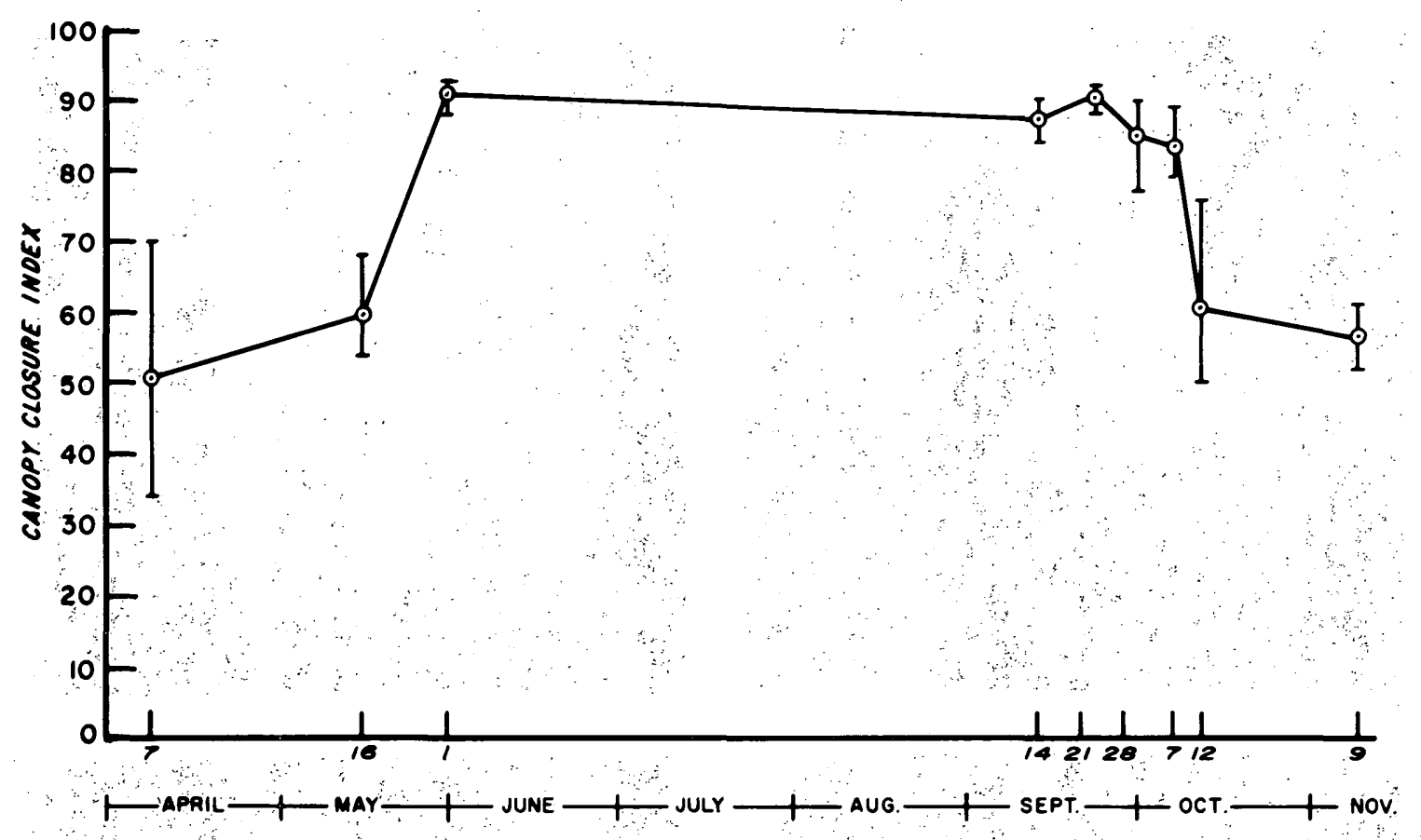

Figure 8. The phenology of the forest canopy at Hubbard Brook Experimental Forest is shown by'a progression of $\mathrm{CCl}$ values for 12 stations in 1966.

may temporarily exceed it. This optimal leaf area, of ten between 3 and $7 \mathrm{~m}^{2} / \mathrm{m}^{2}$, is dispersed and oriented in the canopy volume such that for many forests CCI values tend to cluster around 80 to 85\%. Lesser values are associated with gaps in the canopy. Four diverse forest types are illustrated in Figure 9. The jack pine (Pinus banksiana) forest was lowest because of the open spacing of the stand.

Canopy closure index was obtained for the principal forest types in interior Alaska (Table I). Again high values were from stands with more widely dispersed trees. The lower the CCI, the geater the leaf area inde $x$ of the shrub and ground layer plants. It is evident from the comparisons In Table I that no significant correlations could be found between CCI and tree height, tree density, tree basal area or tree biomass.

A series of conventional photographs was taken with $4 \times 5$-in. panchromatic film of representative forest types in Costa Rica (Table II). The results again demonstr ate a clustering of CCI values just over $80 \%$. Lesser values were related to a deciduous condition or to gaps in the canopy. A subsequent replication with a hemispherical lens conf irmed these value s for similar stands in these life zones in Costa Rica.

During a target detection study with an infrared scanner in Ontario, Canada, military vehicles were concealed within a jack pine (Pinus banksiana) forest and along the edge of the forest and a meadow. As an aid to the interpretation of aerial photography and scanner imagery of the several targets, hemispherical photogr aphs were taken of the canopy over each target. Stem density and diameter were determined for a .1-acre circular plot centered on each target. The forest consisted of a pure stand of 45-year-old jack pine, $15 \mathrm{~m}$ in height with an average diameter of $25 \mathrm{~cm}$. 

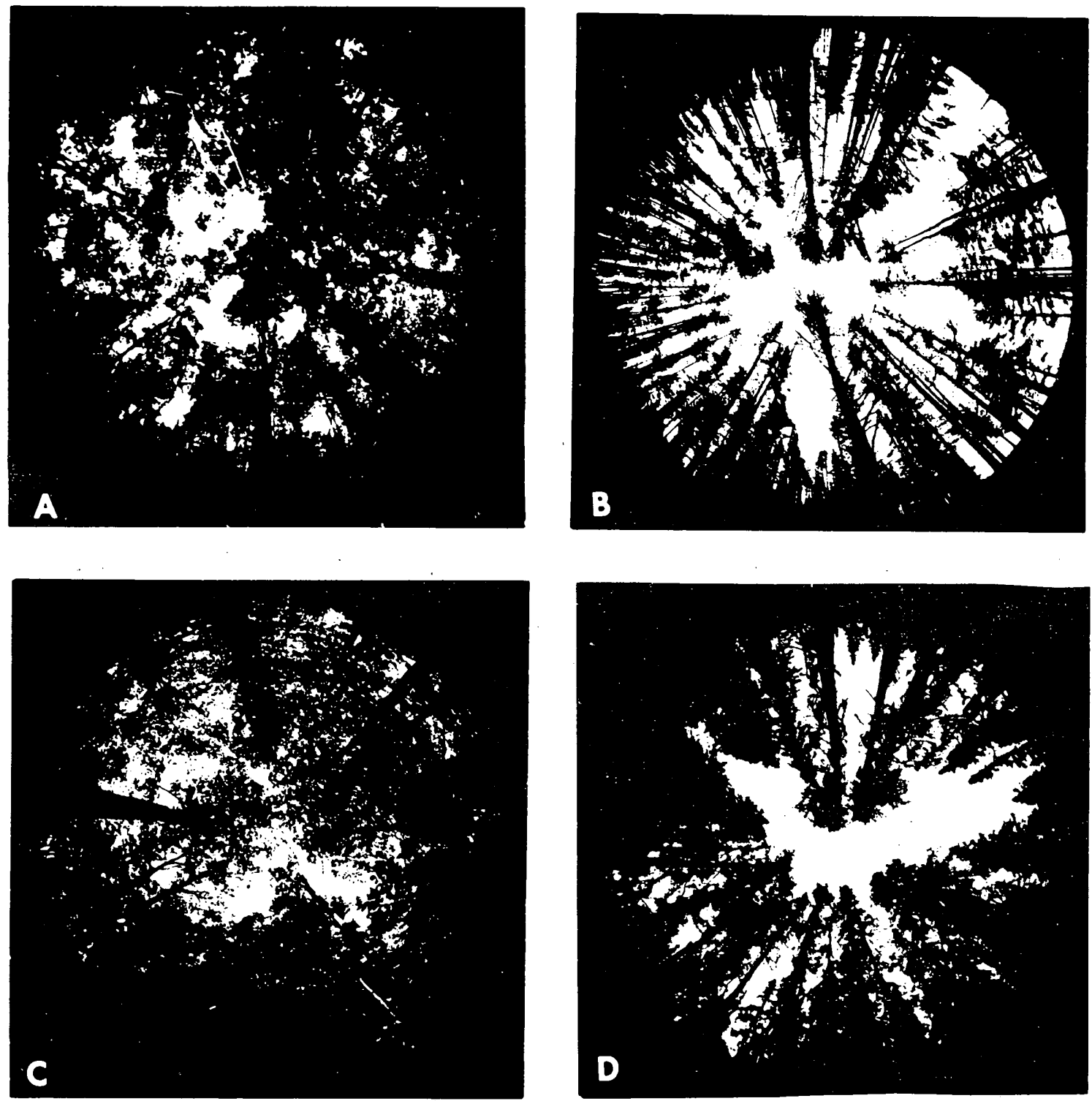

Figure 9. Hemispherical photography of contrasting forest types. A) Northern hardwood forest in New Hampshire, $\mathrm{CCI}=88$. B) Boreal jack pine stand in Ontario, Canada, $\mathrm{CCl}=54$. C) Tropical rain forest in Puerto Rico, $\mathrm{CCl}=84$. D) Subarctic black spruce stand in interior Alaska, CCI = 72.

When the canopy photograph indicated high canopy obscuration directly over the vehicle, detection was not possible. Correlation of CCI values with target detection success involves a number of variables (Leighty and Vogel, 1964); howèver, the canopy photographs were helpful in explaining the nondetectability of targets! No relationship was evident between CCI values and stem density (Table III).

\section{Distribution of leaves and canopy gaps}

The geometry of a forest canopy is difficult to evaluate or even to characterize. The orientation of leaves in a three-dimensional space, their array along a branch and the arrangement and 
Table I. Forest types of interior Alaska, population parameters and associated canopy closure index.

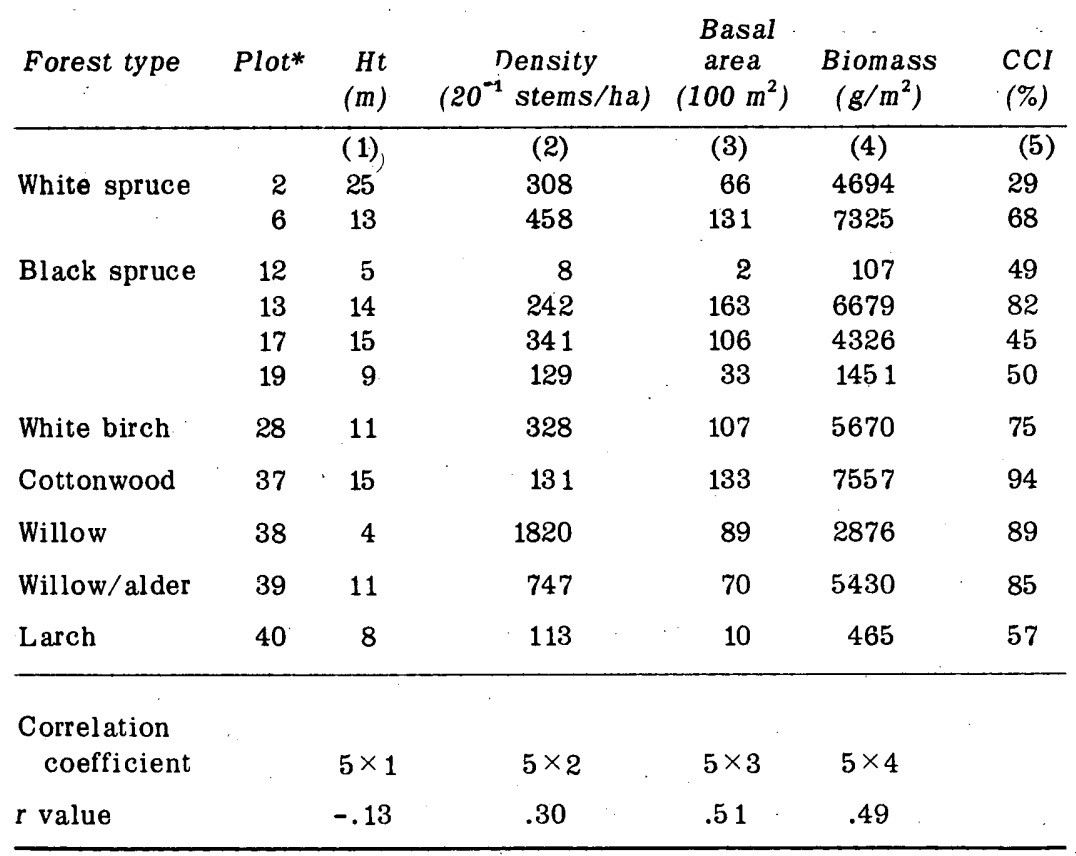

* Plot numbers and population data from Johnson and Vogel, 1966.

Table II. Conventional canopy photographs of tropical forests, Costa Rica. (Photography by courtesy of Tropical Science Center, San Jose.)

\begin{tabular}{llllrl} 
Site & \multicolumn{1}{c}{ Life zone } & Vegetation & CCI & $\begin{array}{c}\text { Elev } \\
\text { (m) }\end{array}$ & $\begin{array}{c}\text { Est } \\
\text { precip. }\end{array}$ \\
\hline 1 D & Tropical dry forest (dry season) & Mixed woodland & 52 & 55 & 1550 \\
1 D & Tropical dry forest (wet season) & Mixed woodland & 92 & 55 & 1550 \\
1 G & Tropical dry forest & Brosium woodland & 65 & 20 & 1700 \\
18 & Premontane moist forest & & 82 & 790 & 1750 \\
3 & Tropical moist/premontane wet forest & 81 & 580 & 2600 \\
4 & Tropical wet forest & & 80 & 600 & 5200 \\
6 & Montane rain forest & 81 & 3120 & 2800 \\
\hline
\end{tabular}




\section{Table III. Stem density and CCI in a Canadian jack pine forest (from Leighty and Vogel, 1964).}

\begin{tabular}{llcc} 
Location & Canopy & $\begin{array}{c}\text { Density } \\
\text { (stems/ha) }\end{array}$ & $\begin{array}{c}\text { CCI } \\
(\%)\end{array}$ \\
\hline A6 & Closed & 2150 & 40 \\
A5 & Closed & 800 & 57 \\
A7 & Closed & 725 & 68 \\
B1 & Closed & 725 & 46 \\
A4 & Closed & 700 & 54 \\
B9 & Closed & 650 & 50 \\
B7 & Edge & 500 & 52 \\
A2 & Closed & 395 & 48 \\
B6 & Edge & 325 & 21 \\
& & 774 & 48 \\
\hline
\end{tabular}

per sistence of branches in a tree crown are apparently a complex interaction between the genetic potential of various species and the environment, particularly the light climate; that the canopy creates.

It is of interest to military detection as well as to seedling regeneration to know the distribution of canopy gaps in the hemisphere above a point. In order to determine the distribution of canopy obscuration with increasing angle from the zenith, nine templates were constructed which permit measurement of obscuration within concentric rings of 5-degree increments. The templates were fabricated by dividing a 90-degree arc into 5-degree segments and then projecting the se segments to a horizontal plane. The areas surrounding the resultant plan view of each 5-degree arc segment were then opaqued, photocopied, and enlarged on film stock to the same scale as the canopy transparencies. : The percentage area of each ring was determined with the macrodensitometer and an area correction factor determined in order to adjust the readings with each ring to equal area expressions. Such values then are an index to target detectability as a function of the angle from the zenith.

In use each ring was placed over the light source and the photometer was zeroed. The canopy photograph was then centered over each iring overlay and the light attenuation read directly in percent transmittance. These values for each 5-degree ring are plotted in relation to the zenith angle (Fig. 10) for a northern hardwood forest without leaves, a pine forest and a montane tropical rain corest. As expected, light penetration is greatest directly overhead and rapidly decreases with increasing slant angle through the canopy volume.

The nature of the photographic process used in our technique depends on the contrast ratio between the sky or overcast and the vegetation. In theory a single leaf should be as effective in producing an opaque image as multiple layers of leaves or stems. In practice lighting on the under surface of some leaves and twigs may reduce the contrast ratio below the threshold for opacity and they become indistinguishable from sky. For this reason the CCI is not directly proportional to leaf area index. Because leaves are dispersed in a three-dimensional volume a leaf area index of 1 does not block the entire sky, nor does a leaf area of 6 , although it is much greater than 1 .

To examine the relationship between CCI and leaf dispersion, a series of hemispherical photographs was taken at vertical intervals from a tower at the Albrook site in a wet tropical forest in Panama. At the end of the dry season in March the CCI values (Fig. 11) were obtained by opaqu. ing half of the hemisphere containing the tower and doubl ing the transmittance on the premise that both halves were of equal canopy configuration. 


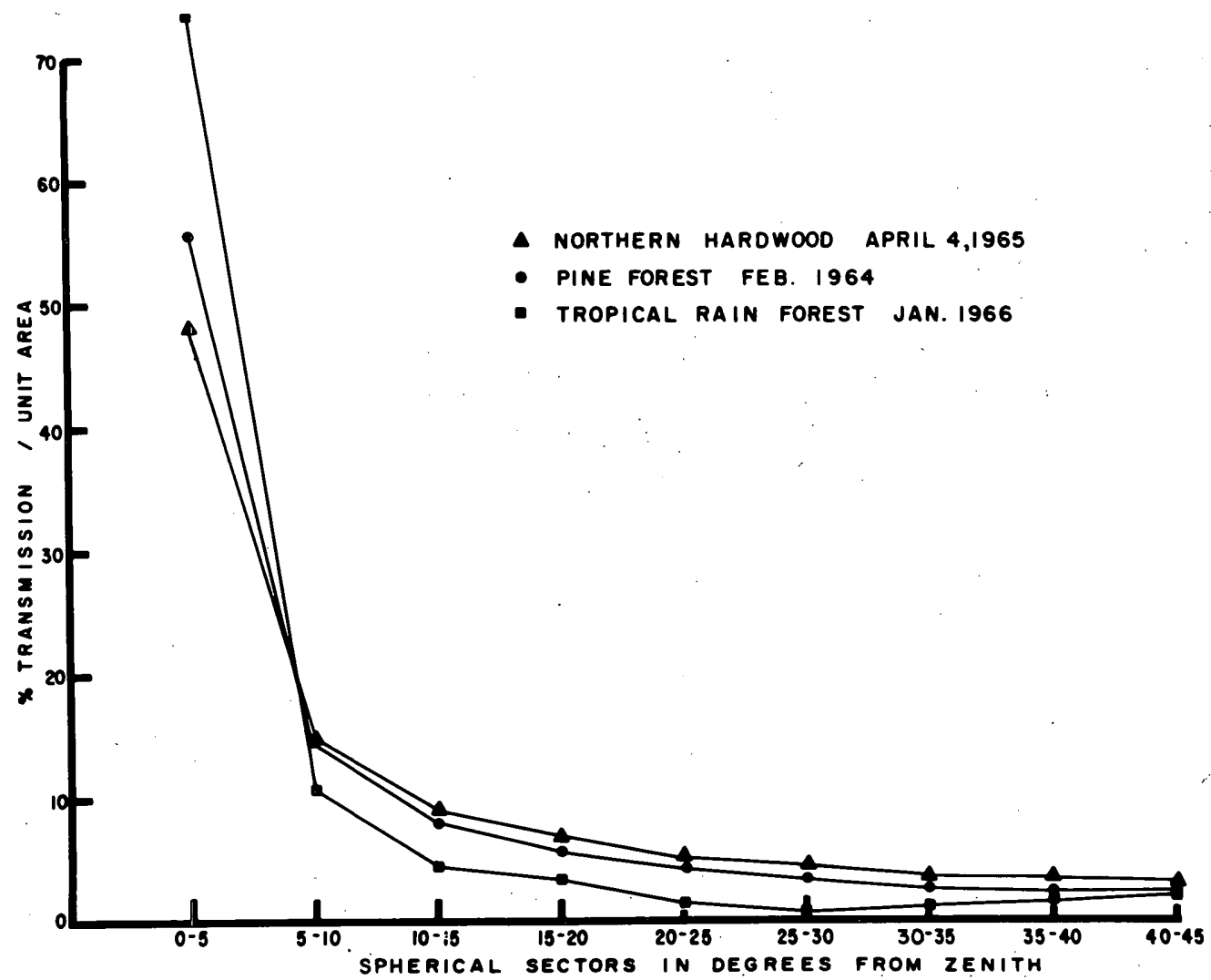

Figure 10. Target detectability in relation to angle from zenith as analyzed from hemispherical photography from three different forest types.

The dispersion of leaves was measured in September by counting the number and height of leaves in contact with a vertically plumbed string. The average of 30 such plumb lines near the Albrook Tower yielded an estimated leaf area index of $4.26 \pm 0.95$ (Tyson, 1966). The vertical distribution is shown in Figure 11. The leaves tended to concentrate below $3 \mathrm{~m}$ and from 16 to $22 \mathrm{~m}$ in this relatively stable secondary stand.

The desirability of an independent measurement of light penetrating the forest became increasingly apparent. Therefore, five Eppley pyrheliometers were installed in the Hubbard Brook Experimental Forest in early May 1967 before vernal activity commenced. One was located in a large clearing to record total incoming short-wave radiation. : The percentage of light on the for est floor at two points, one at Station 1 and the other $123 \mathrm{~m}$ higher at Station 8 , were recorded by measuring the difference in signal between an Eppley pyrheliometer in a clearing and one in the forest. It thus becomes possible to compare an integrated light value for the day penetrating the canopy with CCI values at these two stations. This comparison (Table IV) indicates the decreasing energy available to the ground flora and regeneration caused by phenology of the overstory. The pitfalls of a more precise relationship were discussed earlier as well as by Anderson $(1964,1966)$ and U.S. Army Corps of Engineers (1951).

\section{Light quality}

One of the more important effects of light attenuation by tree crowns is the differential filtering of wavelengths. The light quality of shade near a building is predominantly blue because of the greater scattering of shorter wavelengths by the atmosphere. Forest shade, on the other hand, 

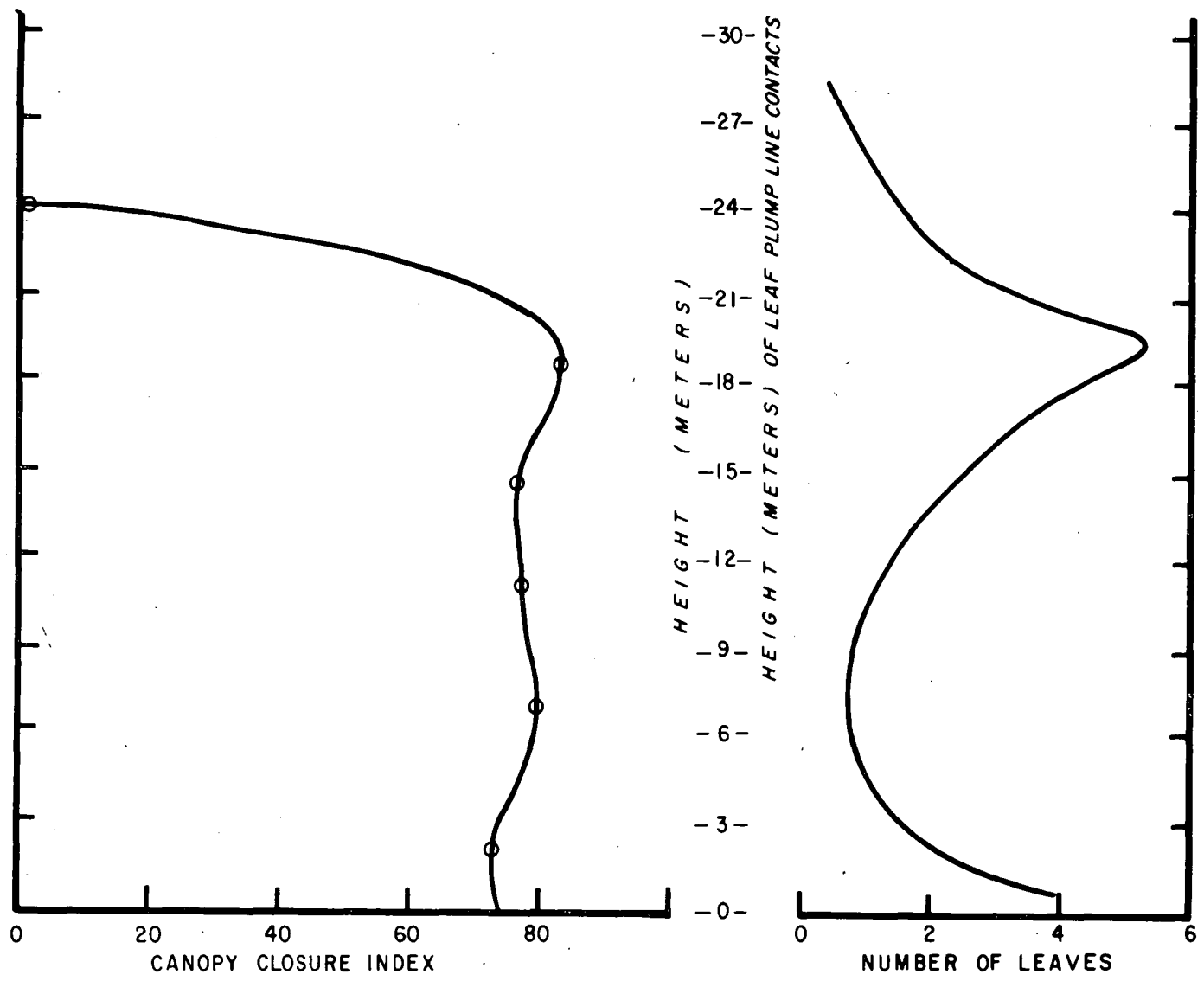

Figure 11. Comparison of CCI values at different heights in a forest with a vertical profile of leaf numbers in a Panamanian semi-evergreen forest.

Table IV. Comparison of Canopy Closure Index (CCI) with measurements of solar energy penetrating to the forest floor at Hubbard Brook Experimental Forest.

\begin{tabular}{|c|c|c|c|c|}
\hline Date & $\%$ Full su & ht, 24 hours & & $C C I$ \\
\hline & 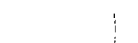 & Station 1 & & \\
\hline $18 \mathrm{May}$ & 56 & & & 34 \\
\hline 6 June & 40 & & & 79 \\
\hline 12 June & 35 & & & 89.5 \\
\hline 21 June & 44 & & & 87 \\
\hline 5 July & & & $r=0.91$ & \\
\hline & 1 & & & \\
\hline & 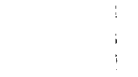 & Station 8 & & \\
\hline $18 \mathrm{Ma} y$ & 62 & & & 27 \\
\hline 6 June & 35 & & & 75 \\
\hline 12 June & 22 & & & 79 \\
\hline $21 \mathrm{June}$ & 20 & & & 85 \\
\hline $5 \mathrm{July}$ & & & $r=0.97$ & \\
\hline
\end{tabular}




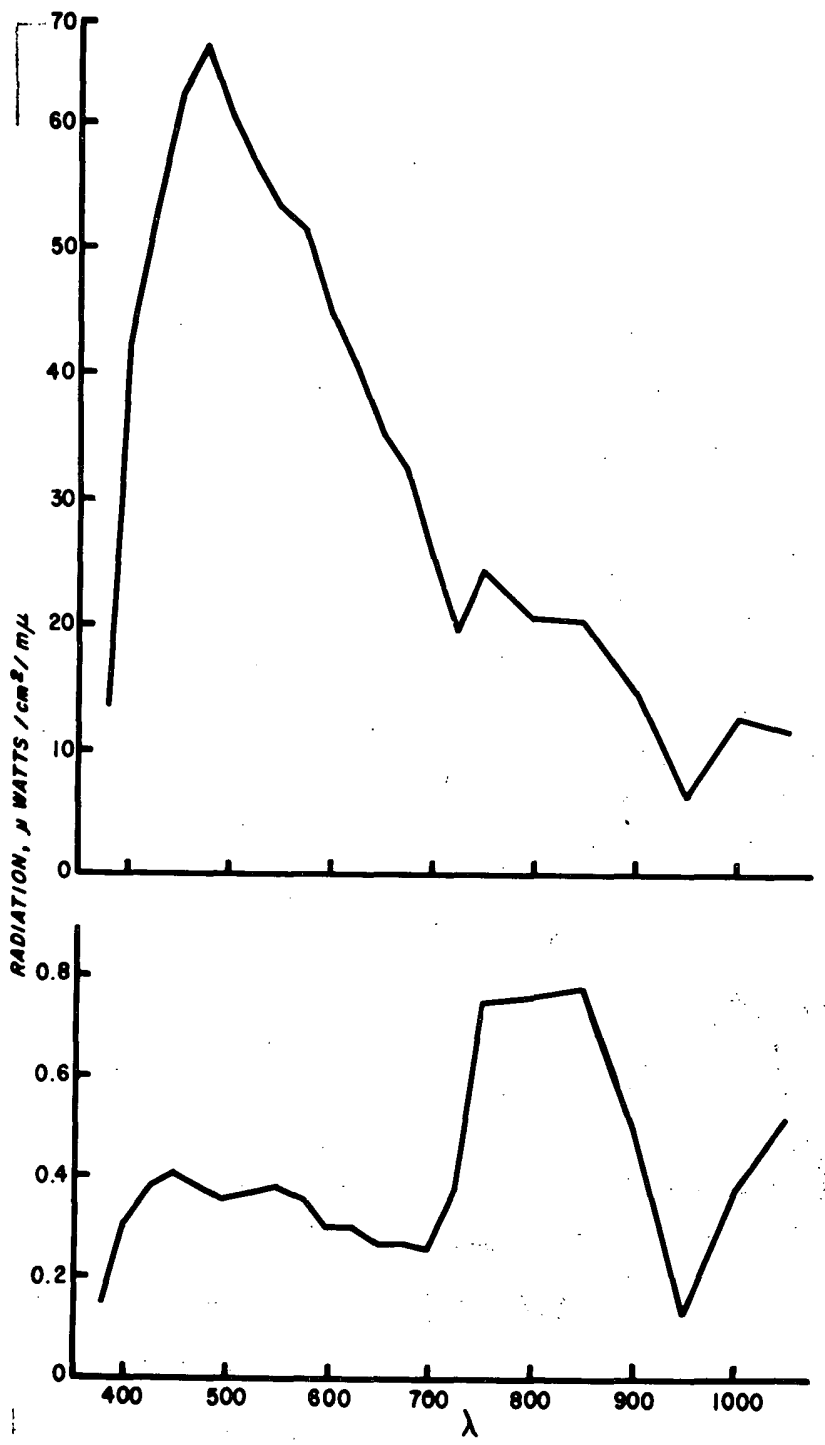

Figure 12. Sunlight (upper) and forest shade light (lower) intensity by wavelength in a Puerto Rican evergreen montane rain forest. is dominated by near infrared wavelengths, especially $750-850 \mathrm{~m} \mu$ (Johnson and Atwood, 1968). Sunlight above the canopy of a montane rain forest ne ar El Verde, Puerto Rico, and shade light reaching the forest floor were measured in April 1966 and March 1967 with a battery-powered spectral radiometer (ISCO Model SR). : This instrument indicates the incident energy in $\mu$ watts $/ \mathrm{cm}^{2} / \mathrm{m} \mu$ in the $\mathrm{r}$ ange $380-1050 \mathrm{~m} \mu$ by use of a narrow band interference wedge and a photo diode circuit. The bandpass of the instrument is approximately $20 \mathrm{~m} \mu$ wide. The data (Fig. 12, 13) have been adjusted by calibration of the instrument to a standard lamp.

Although the percentage of direct sunlight reaching the forest floor was less than 1.5, the proportion of this infrared energy $(700-1000 \mathrm{~m} \mu)$ was doubled compared with full sunlight incident at the top of the canopy (Fig. 12). This difference in light quality within dense forests may be especially important in the ecesis of successional species since several growth processes are partially wavelength-dependent.

A similar shift in light quality occurs in deciduous forests during leaf expansion and leaf drop. Figure 13 indicates the distribution and amount of energy reaching the forest floor of the Hubbard Brook Experimental Forest in New Hampshire in winter and late summer. During the leafless period $2 / 3$ of this energy was in the near infrared spectrum. : The extent to which the vernal ground flora, that essentially completes its annual growth and reproduction before leaf expansion, has evolved in response to light quantity or quality is unknown.

\section{DISCUSSION AND SUMMARY}

Forest canopies are rather eas ily evaluated with hemispherical photography and a macrodensitometer. The attributes of a divergent lens system were apparently first applied to forests by Evans and Coombe (1959) using the Hill camera. The improvement of optics and film speeds now permits sharp hemispherical photography of canopies either for evaluating canopy development, for estimating the light climate, or for specifying target detectability. Such photography can be efficiently evaluated with a macrodensitometer, although our experience suggests that more consistent results are realized from photographs obtained under overcast conditions. 


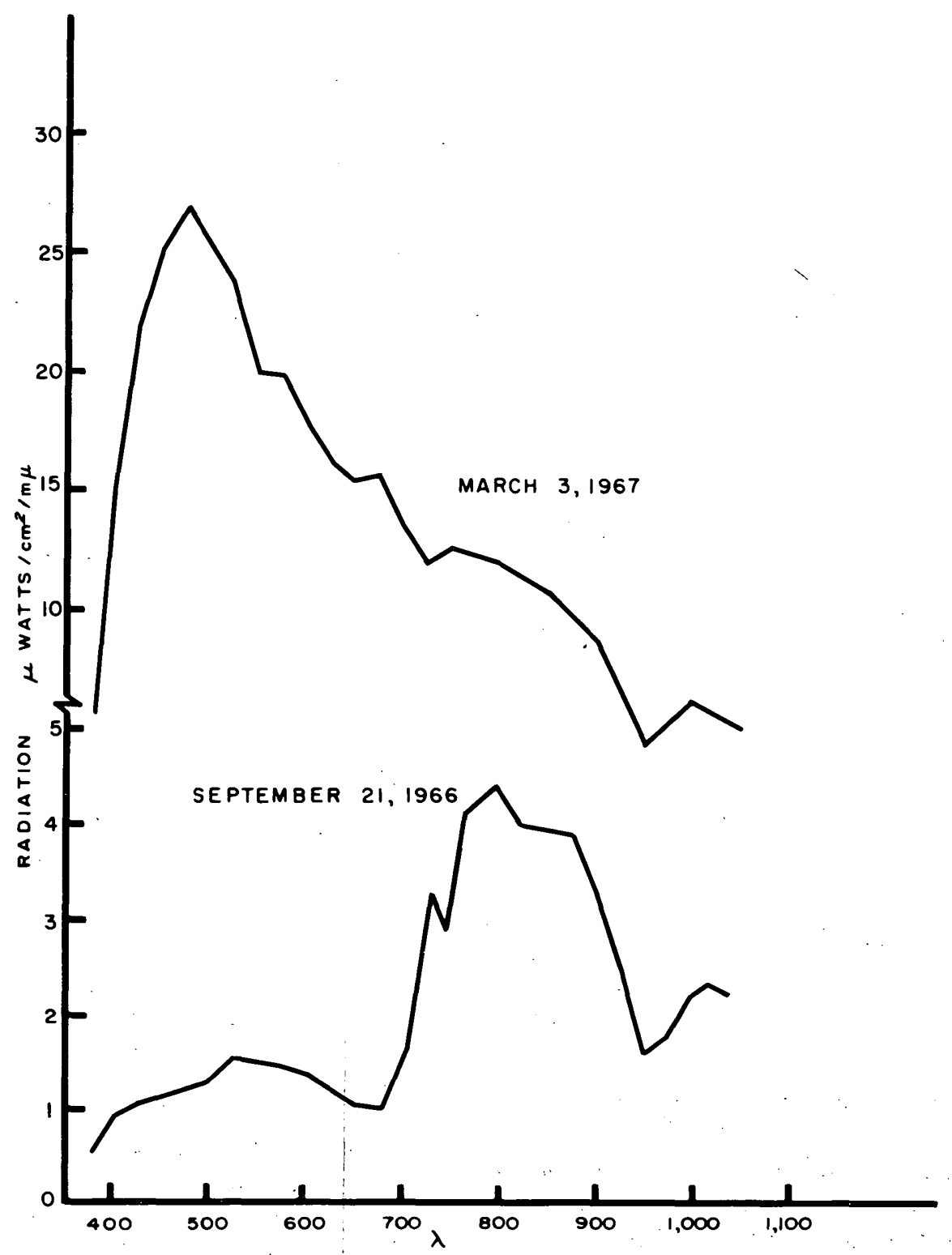

Figure 13. Winter (upper) and summer (lower) light intensity by wavelength on the forest floor of a northern hardwood forest in New Hampshire. The spectral distribution is similar, but the intensities are quite different.

The precision of this technique appears to be at the $5 \%$ level; however, the precision will vary in response to several variables, not all of which need influence a given application. To reduce the influence of the initial exposure determination, each site was bracketed with several exposures. Optimal processing of the Kodalith transparency was somewhat dependent on the skill and judgment of the darkroom technician and variations due to processing became more significant when the experiment required replication in a time series. Replication of the readout system was easily held below a $2 \%$ error. Small variations in the height of the camera and positioning of the transparency in the macrodensitometer did not greatly influence the results. Small differences in reoccupying the same camera point may completely invalidate the comparison; therefore, the use of a pipe as a permanent camera support was adopted. The utility of this technique of evaluating 
forest canopies was demonstrated by a wide spectrum of applications. There is no better rapid and accurate method of measuring canopy development. The values obtained can be compared spatially or temporally, and a pictorial record is retained of each data site.

Comparison of values from contrasting types of vegetation structure suggest a similarity in the leaf area that can be supported independent of tree height or species. The higher values measured in wet tropical forests $(\mathrm{CCI}=90)$ presumably reflect the structural and species diversity that have evolved there. High latitude forests must contend with lower.sun angles as well as increasing environmental severity.: Apart from forests, the highest CCI values are to be expected in early stages of rapid plant succession such as raspberry patches (Rubus spp.) or beneath dense herbaceous stands. : In the former case, the leaves beyond the light compensation point soon perish. : In the latter case, certa in herbaceous and moss species have greater shade tolerance than trees.

Two problems have been avoided by using Kodalith transparencies with opaque images; the leaf extinction coefficient was not a consideration and variations in film processing were minimized. Should an investigator seek to apply this technique to estimates of leaf area or to optical density and biomass (Odum et al., 1963), then an integrated gray tone of a panchromatic transparency is desired. However, both of the above considerations must then be satisfied. Whittaker and Woodwell (1967) have successfully estimated the branch wood surface area of a forest with this technique.

Consideration of light penetrating a canopy to a seedling involves integrating the area of gaps in a hemisphere. The probability of detecting a target by line-of-sight through a canopy from an aerial platform is a function of the distribution of gaps. It has been shown that the probability of detection decreases rapidly with departure from the zenith. Although wind movement and growth may vary the dispérsion of individual gaps, vertical obscuration or detection angle can be rapidly analyzed from hemispherical photographs.

There is a considerable shift in the ratio of visible to in frared wavelengths from sunlight to forest shade light. Although the intensity of solar radiation may be much less in wet tropical forests than in broadleaf temperate forests, a similar light quality is suggested. This change from $2 / 3$ visible wavelengths of sunlight to $2 / 3$ infrared energy (with in the range of measurement, 400 to $1000 \mathrm{~m} \mu$ ) occurs during the period of rapid leaf expansion. The biological implications of such a rapid shift in light quality are not fully understood, although the magnitude and timing of the shift could be approximated from measurements of canopy closure index.

\section{LITERATURE CITED}

Anderson, M.C. (1964a) Light relations of terrestrial plant communities and their measurement. Biological Reviews, vol. 39, p. 425-486.

(1964b) Studies of the woodland light climate. I. The photographic computation of light conditions. Journal of Ecology, vol. 52, p. 27-41.

(1966) Stand structure and light penetration. IIA. Theoretical analysis. Journal of Applied Ecology, vol. 3, p. $41-54$.

Bormann, F.H. (1956) Percentage light readings, their intensity-duration aspects, and their significance in estimating photosynthesis. Ecology, vol. 37, p. 473-476. and Likens, G.E. (1967) Nutrient cycling. Science, vol. 155, p. 424-429.

Brown, H.E. (1962) The canopy camera. U.S. Forest Service, Rocky Mountain Forest and Range Experiment Station, Station Paper 72, p. 1-22.

Evans, G.C. and Coombe, D.E. (1959) Hemispherical and woodland canopy photography and the light climate. Journal of Ecology, vol. 47, p. 103-113.

Johnson, P.L. (1965) Monitoring radioactive contamination to vegetation with aerial photography. Photogrammetric Engineering, vol. 31, p. 984-990; - 
Johnson, P.L. and Vogel, T.C. (1965) Canopy closure index by an optical density method. U.S. Army Cold Regions Research and Engineering Laboratory Technical Note (unpublished).

(1966) Vegetation of the Yukon Flats region; Alaska: U.S. Army Cold Regions Research and Engineering Laboratory (USA CRREL) Research Report 209.

Johnson, P.L. and Atwood, D.M. (1968) Aerial sensing and photographic study of the El Verde Rain Forest, Puerto Rico. In $A$ rain forest. U.S. Átomic Energy Commission (in press). Also USA CRREL Research Report 250 (in press).

Leighty, R.D. and Vogel, T.C. (1964) Infrared detection of military vehicles on a snowcovered background (U). USA CRREL Technical Report 155 (Confidential).

Monsi, M. and Saeki, T. (1953) Uber den Lichfactor in den Pflanzenge svell schaften und seine Bedeutung fur die Stoffproduction. Japanese Journal of Botany, vol. 14, p. 22-52.

Odum, H.T.; Copeland, B.J. and Brown, R.Z. (1963) Direct and optical assay of leaf mass of the lower montane rain forest of Puerto Rico. Proceedings National Academy of Sciences, vol. 49 , p. $429-434$.

Reif snyder, W.E. and Lull, H.W. (1965) Radiant energy in relation to forests. U.S. Forest Service Technical Bulletin 1344, p. 1-111.

Rinker, J.N.; Johnson, P.L.; Vogel, T.C.; Morgan, J.O.; Parker, D.C. and Fisher, D.S . (1963) Infrared detection of heat sources obscured by tropical rain forest vegetation (U). USA CRREL Research Report 149 (Confidential).

Saeki, T. (1963) Light relations in plant communities. In Environmental control of plant growth (L.T. Evans, Editor). New York: Academic Press, p. 79-94.

Tyson, E. (1966) Annual report, data base project. U.S. Army Tropic Test Center, Fort Clayton, Panama, C.Z.

U.S. Army Corps of Engineers (1951) Transmission of shortwave radiation through forest canopy. Research Note SPPGC 627-51, p. 1-19 (mimeo).

Vogel, T.C. (1967) Evaluation of forest blowdown from aerial photography.(U). USA CRREL Technical Report 203 (Confidential) (in press).

Whittaker, R.H. and Woodwell, G.M. (1967) Surface area relations of woody plants and forest communities. American Journal of Botany (in press).

Woodwell, G.M. and Rebuck, A.L: (1967) Effects of chronic gamma radiation on the structure and diversity of an oak-pine forest. Ecological Monographs, vol. 37, p. 53-69. 
Unclassified

Security Classification

\section{DOCUMENT CONTROL DATA - R \& D}

(Security classification of title, body of abstract and indexing annotation must be ontered when the overall report is clasellied)

1. ORIGINATING ACTIVITY (CoTPORATO

Cold Regions Research \& Engineering Laboratory

U.S. Army Terrestrial Sciences Center, Hanover,

New Hampshire

3. REPORT TITLE

EVALUATION OF FOREST CANOPIES BY PHOTOGRAPHY

4. OESCRIPTIVE NOTES (Typo of roport and inclusive dates)

Research Report

5. AU THOR(S) (Firat namo, middlo initial, last namo)

Philip L. Johnson and Theodore C. Vogel

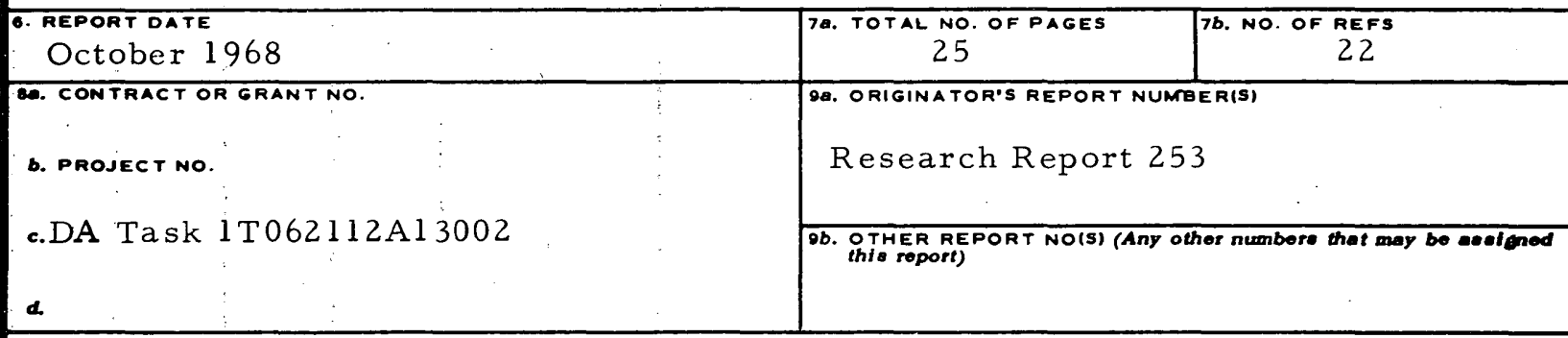

10. DISTRIBUTION STATEMENT

This document has been approved for public release and sale; its distribution is unlimited.

\begin{tabular}{|l|l}
\hline 11 SUPPLEMENTARY NOTES & $\begin{array}{l}\text { 12. SPONSORING MILITARY ACTIVITY } \\
\text { Cold Regions Research \& Engineering } \\
\text { Laboratory } \\
\text { U.S. Army Terrestrial Sciences Center }\end{array}$ \\
\hline
\end{tabular}

13. ABSTRACT

A technique for evaluating forest canopies was developed based on the use of a divergent lens system to obtain hemispherical photographs of tree crowns. The photography was processed from $35 \mathrm{~mm}$ film and enlarged as a silhouette, and the light transmission was measured with a specially fabricated macrodensitometer. It is concluded that the amount of forest canopy can be expressed as canopy closure index (CCI) at a precision of approximately $5 \%$. It is shown by application to a variety of problems in diverse geographical areas that this technique can be used for measuring both temporal and spatial changes in the canopy, for estimating the shade light climate, and for specifying the probability of target detection through a canopy. Data are presented to analyze changes caused by explosions, radioactivity, growing season, and vegetation types. The geometry of gaps in tree crowns is discussed and the nature of shade light quality under forests is illustrated. 
Unclassified Security Classification

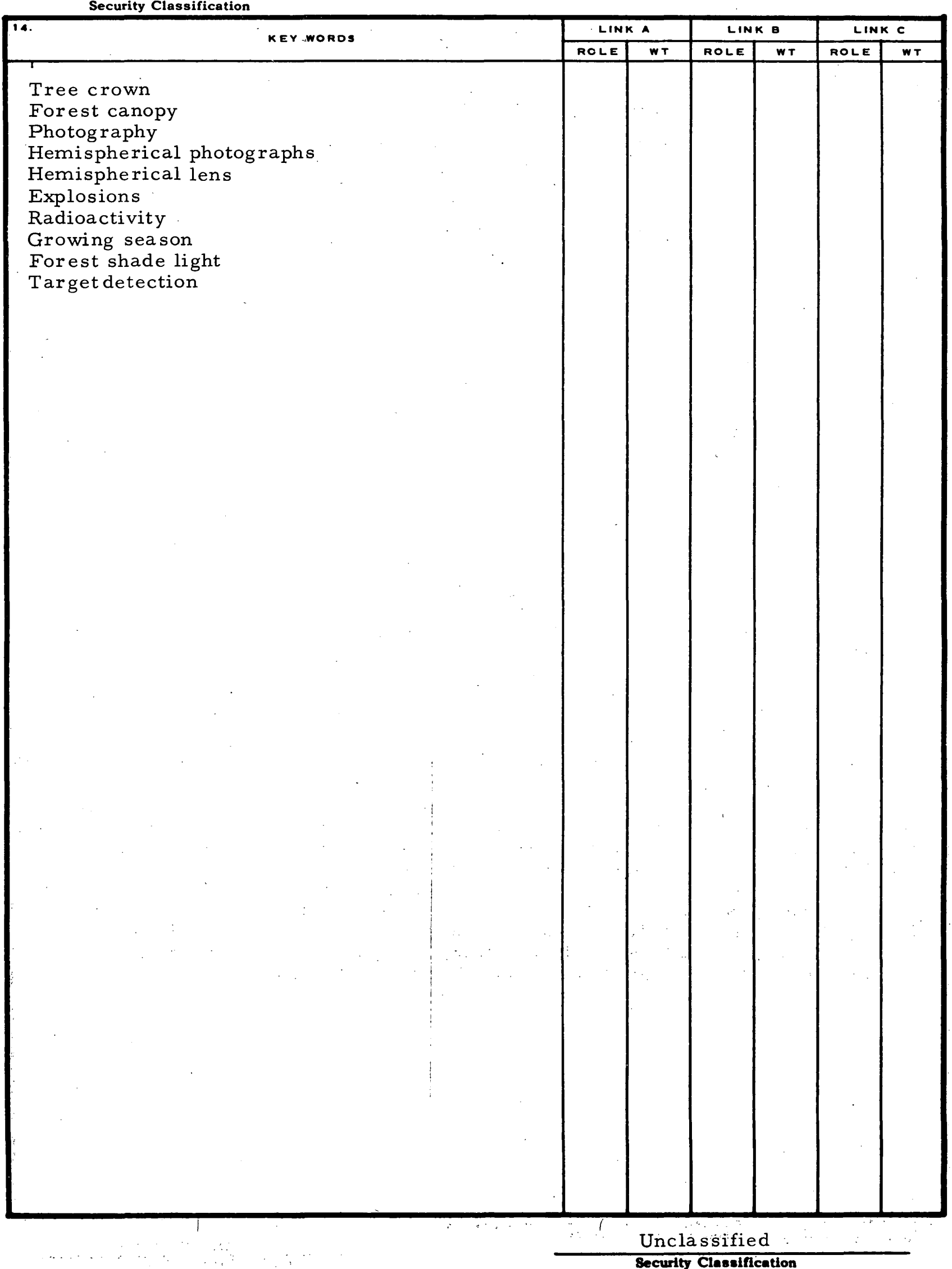

